\title{
Present Application Status and Prospect of Bryophytes in Landscape Architecture*
}

\author{
Xiaoyu Ming \\ College of Landscape Architecture \\ Sichuan Agricultural University \\ Chengdu, China \\ Panpan Cao \\ College of Landscape Architecture \\ Sichuan Agricultural University \\ Chengdu, China \\ Linyun Tan \\ College of Landscape Architecture \\ Sichuan Agricultural University \\ Chengdu, China
}

\author{
Yufan Ding \\ College of Landscape Architecture \\ Sichuan Agricultural University \\ Chengdu, China \\ Chunnong Li \\ College of Landscape Architecture \\ Sichuan Agricultural University \\ Chengdu, China \\ Xiaofang $\mathrm{Yu}^{*}$ \\ College of Landscape Architecture \\ Sichuan Agricultural University \\ Chengdu, China \\ *Corresponding Author
}

\begin{abstract}
This paper summarized the research progress, application value and status of bryophytes, introduced its collocation with other landscape elements. The goal of this paper is to provide certain theoretical basis and design suggestions for landscape application of the bryophytes in future, at the same time, gave some bryophytes configuration mode and ideas for the landscape architects.
\end{abstract} status

Keywords-bryophytes; landscape application; application

\section{INTRODUCTION}

Bryophyte, as a significant part of biodiversity in nature, is always neglected in Chinese landscape architecture. The successful use of bryophytes in planting landscape proved the great potential of bryophytes in landscape application. The karesansui of longan temple built in Ukyo-ku, Kyoto-shi in fifteenth Century is the most famous garden product in Japan. Taking white sand, brown stone and bryophytes as the subject matter, the masterpiece of the karesansui reflecting Zen Buddhism is the representative of abstract beauty.

The application of bryophytes in the garden was tried from the starting point of bryophytes specialized garden, and some bryophytes were concentrated in a certain range for the design of the theme plant materials with the rocks and water. In 2006, Jiao Yunhong concluded that bryophytes park is a botanical garden with bryophytes as the main plant materials, combined with stones, waterscape, trees and other gardening factors, following the rules of ecology and the principles of landscape art design, which can show the green color beauty

*Thanks for Guangdong provincial science and technology project (2017B090907001). of bryophytes (Jiao Yunhong, 2006). After that, Zhou Zhijing classified and explained the application of bryophytes in 2009 for the first time. She divided the application of bryophytes into 9 categories: bryophyte, bonsai, indoor garden, etc (Zhou Zhijing and Zhu Yalan, 2009). In 2010, with the support of Shenzhen Urban Management Bureau, a bryophytes production nursery, has been set up in Xian lake botanical garden for artificial propagation of bryophytes. The researchers screened a variety of bryophytes suitable for the local artificial breeding in Shenzhen, through field investigation and introduction to Southern China. Many artificial breeding methods, such as planting method, ramet method, bud differentiation method, container cultivation method and natural inoculation method, were successfully used. At present, the artificial production of bryophytes has begun to take shape, and the application of bryophytes in landscape is gradually explored, such as bryophytes bonsai, bryophytes bottle garden, bryophytes small products and so on, and has achieved good results. In spite of the late start of the study in China, the application of bryophytes in the landscape is strengthened through the gradual accumulation of experience, and the application of bryophytes in the landscape is strengthened. The landscaping material of the garden is more abundant and the landscape of the city is more diverse (Chen Jun and Chiang Ming, 2010).

The bryophytes Garden in Daekwon Park, Quebec, Canada, shows bryophytes in the form of winding composition, stereoscopic way, and decorative screen on the basis of modern style. It is reported that in March 2012, Indonesia opened the world's largest bryophytes specialized garden, which belongs to the Cibodas botanical garden, the Cibodas bryophytes park. 
As for the design method of bryophyte specialized garden, Sun Jun Feng has his own understanding. At the beginning of the construction of the bryophytes specialized garden, we should pay attention to the protection of natural resources, do not overdose the plucking, pay attention to local conditions, highlight local characteristics and endemic germplasm resources. In the aspect of plant landscaping, the simulation of natural bryophytes communities should be "alike in spirit" and not merely in pursuit of expansion of cultivated area (Sun Junfeng, 2013). The natural bryophytes community often covers a vast area, so the landscape is very shocking. In the short term, the artificial bryophytes Garden should highlight the unique ingenuity and charm through creative design.

\section{THE GARDEN APPLICATION VALUE OF BRYOPHYTES}

\section{A. Aspland}

When it comes to pioneer plants, water storage and soil conservation, environmental indicator plants, it is hard to think of short and small bryophytes. However, bryophyte is an indispensable part of the ecosystem. Its ecological significance and value are far more important than we think.

1) Pioneer plants: Many species of bryophytes have strong drought resistance. They can be born on bare rocks and on new fractured rocks. They are rich in various dry substrates, following bacteria, and after cyanobacteria. They use their dense clusters of water and dust to break down rocks surface with their acid metabolites, and eventually to promote its differentiation. This process is slow, but after a long period of time, this tiny effect gradually accumulates, which will make plants have a place to live in. For example, after the growth of granite and sandstone on the purple calyx bryophytes, there are often plants of the family Sedum. $\mathrm{Xu}$ Jie believed that as the main pioneer plant in the process of environmental succession, the bryophytes participated in the formation of soil crust and played an irreplaceable role in the improvement of biological sand control, sand fixation and ecological environment, and played a unique role in the development and maintenance of the fixed sand dune knots and the evolution of the sandy ecosystem (Xu Jie 2003).

2) Water storage and soil conservation: Although bryophytes are small in size, their interlaced branches and leaves will form a large number of capillary pores, which will absorb water very quickly and require large amount of water. For individuals, Sphagnum acutifolium accounts for $94.3 \%$ of its own weight (Hao Zhanqing, 2000). For communities, the sphagnum community can absorb moisture equal to 30 times its own weight (Chen Bangjie and Wu Pengcheng, 1964). The saturated storage capacity of bryophyte communities in Changbai Mountain Abies forests in Northeast China is 3-5 times the dry weight, reaching 24.56 28.56 tons / ha (An Li and Cao Tong,2006). The maximum water holding rate of bryophytes under Abies fir forests in Gongga reaches 1195.85\% (Chen Lihua and Yu Xin Xiao, 2002).
Bryophytes can effectively slow down the direct impact of rainfall on the surface soil, especially the erosion and splash of the rainstorm, the capillary tube of the bryophyte layer can quickly absorb the rainfall and release slowly. It effectively regulates the surface runoff and water conservation in the drought period, and maintains the wetness of the environment. With the increase of annual rainfall, the biomass and interception ability of bryophytes increased correspondingly, and showed a significant positive correlation with excess rainfall (Herben, 1984).

3) Environmental indicator plants: Bryophytes are extremely sensitive to air pollution, which are as much 10 times as spermatophyte. Bryophytes are great to be indicative plant (Cameron \& Nickless, 1977). Investigating the distribution and composition of bryophytes community and the growth of individual plants and detecting the chemical content of pollutants in the body can reveal the extent of air pollution. Wei Haiying and An li (Wei Haiying, 2004)believed that bryophytes are sensitive to heavy metals in the environment and absorb large amounts of heavy metals, which has important value in environmental monitoring, heavy metal pollution study. Bryophytes can indicate carbon dioxide, chloride, ozone and some metallic ions, which are most sensitive to aluminum pollution.

\section{B. The Ornamental Value of Bryophytes}

The ornamental value of bryophytes is mainly reflected in the form and color of growth. The former is decided by the growth pattern of bryophytes. According to the summary of M. Schuster, bryophytes are divided into five types: cushion, tree, tile, interlacing and drape. As for colors, there are green, bright green, dark green, and brown green. Some species are greyish green, yellowish brown, brown, red, black or gray, and some species are glossy.

\section{The StATUS OF GARDEN APPLICATION OF BRYOPHYTES PLANTS}

\section{A. Macroscopic Aspect}

1) Bryophytes garden: The use of bryophytes in Japanese gardens was earlier, its history can be traced back to the time of nara (12th century). The Xifang temple is Japan's most famous bryophytes park, also known as tai temple, its predecessor was the holy crown villa renovation of the temple, built in 1339 by Mengchuangshushi to build again. In addition to the Xifang temple, some famous Japanese gardens are also known for bryophytes, such as the Cizhao temple, the Tihu temple, the Dade temple, the Luyuan temple and more.

There are currently dozens of bryophytes courts in Japan. Bryophytes have a relatively short history of garden application in European and American countries. The United States can date back to the 1930s, but the development is slow. In the 1970s, there were 37 kinds of bryophytes gardens in Britain and 57 kinds of bryophytes gardens in Holland in 1982. In recent years, the use of bryophytes to build gardens in European and American countries has 
become very popular, and there have been companies and websites specializing in growing and selling bryophytes.

Most of the bryophytes are used in the landscape construction of the bryophytes in the large field of view of the park. Choosing suitable sites for moss growth, focusing on a variety of bryophytes as the theme of landscaping, to win the group effect, giving people a visual shock. Bryophytes gardens can be divided into two kinds, one kind is Stroll Garden (touring Garden), and another kind is Contemplation Garden (coagulation to admire the Garden). Stroll Garden is a place where visitors can stroll along the trail and mingle with the garden. Visitors to Contemplation Garden are not allowed to enter, but can only view from afar, such as the karesansui garden of the Longan temple in Kyoto (Chen jun and jiang Ming, 2010).

Different bryophytes are planted around gardens, waterscape, rockery, garden buildings and garden roads to create an ecological environment suitable for bryophytes growth and match with other plants to complement each other. For example, in the open courtyard, the plants of Polyt r ichaceae, Leucobryum, Hypnum, etc., are dotted with some flowers, trees and small garden ornaments. The beautiful and elegant scenery is everywhere. In the garden pond, Riccia fluitans and so on, not only make the water scene more lively and beautiful, but also replenish the oxygen in the water. On the rockery, some bryophyteses, such as the Thuidium of the Haplocladium, disguise the traces of artificial construction and add to the natural landscape, giving a sense of rustic elegance. On top of the building or pedestrians visible and hard to reach place, selecting suitable bryophytes species, such as twisted mouth bryophytes (Barbula) grey bryophytes genera (Leucobryum) really bryophytes (Bryum) etc., for artificial cultivation, growth environment, or to create suitable for bryophytes consistently high humidity (90\%) temperature $25 \sim 30^{\circ} \mathrm{C}$, a certain amount of scattering light, etc. (Li Xueye, 2008), about a month or so, some bryophytes species like Fissidens and Philonotis can grow spontaneously. The conservation and management of these bryophyteses will soon be able to add a natural green blanket to the building, which will make the visitors feel happy and relaxed. In the design process of the bryophyteses special garden, light, angle and season should be taken into consideration to show the different character of bryophytes, showing the unique and elegant scenery of the moss.

2) Other special gardens: Another application of bryophytes in macro landscape garden is that bryophytes can be in other botanical garden theme or speciality area as associated plants. In the orchid gardens garden, often cultivated as associated plants, bryophytes not only created a suitable ecological environment for orchis growth, but also played a role of beautification. In the shade plant area, a large amount of bryophytes is often cultivated artificially or generated naturally, making the whole area more elegant and beautiful. In some special botanical gardens, bryophytes are often laid on the small garden ornaments to enhance their image and beautify, such as the application of bryophytes in orchid garden of Singapore botanical garden.
3) Kare-sansui garden: Kare-sansui garden in anhydrous conditions, through the combination of stone and sand using simulating water feeling faint, sometimes also with plant for sand. It is one of the features of the Japanese garden, such as the Kyoto Long An temple, in the garden without a tree and one grass, through the ingenious conception, through the arrangement of block stone, the spread of white sand, and the bryophyte ornament, it abstracts into the sea, the island and the forest, and turns out another realm. In the modern garden, many masters of genres such as minimalist, earth art Peter Walker, Martha Schwarz and others are more or less affected by the thought of landscape garden. Their garden works often contained dry Kare-sansui garden seal and artistic conception.

\section{B. Medium Aspect}

1) Indoor garden: Indoor gardens are often insufficient lighting, poor drainage. However, the bryophytes plants can adapt to the habitat, and provide other indoor ornamental plants with good growth of green base, with a pile of stone, making people never leave home can enjoy the landscape of interest, at the same time bringing indoor small and exquisite, natural and pure and fresh breath bryophytes green, and blue green wood and cleverly into the courtyard of the flowers and plants, constituting the elegantly quiet and thoughtful pictures, however, to become human and the nature's masterpiece.

2) Roof garden: Bryophytes of roof greening mainly through reasonably consider roof bearing plant landscape water body configuration, and carefully select variety of bryophytes to create a suitable for bryophyte growth environment and build the bryophytes landscape. Bryophytes division is bryophytes courtyard greening in early adoption of form, and temples together. Most of them is Japan's most famous Kare-sansui gardens commonly used technique of expression, the forest by configuration, the bryophytes and sandstone show an ancient artistic conception of dull and lonely, with the development of the society. Bryophytes court further open to the public, gradually developed into a park for people to tour the bryophytes besides bryophytes park. Modern roof garden using bryophytes landscape layout is also very common. Its configuration and symbolism also greatly beyond the ideas of the dry landscape garden, is the most typical technique. The most typical method is to create a very open sense in the narrow space through the small size of bryophytes. The roof moss gardens create various microclimate environments through micro topography and form rich moss landscapes. Forming a rich bryophytes landscape is given priority to with bryophytes of roof garden, often as high as dozens of bryophytes plants, commonly used bryophytes have Leucobryum, Leucobryum $\mathrm{j}$ uniperoideum, Polyt $\mathrm{r}$ ichaceae, Polytrichum commune, Polytrichum commune Hedw., Hypnaceae, etc.. 
3) Greening of grey space: Most bryophytes are highly adaptable and can grow well in grey spaces such as the back of the rockface on the trunk of the trunk of the tree under the shade of the roof forest. The designer of balmery joint design office in the UK has built a bryophytes wall using lightweight plastic net technology. Its landscape effect is like "tapestry", which is pleasing to the eye.

\section{Microcosmic Aspect}

1) Vertical greening: With the impact of global climate change, ecological architecture has become a hot spot in the world. Bryophytes have become the ideal materials for the development of ecological architecture because of their advantages of strong adaptability, less medium demand and light weight. Bryophytes vertical greening methods mainly in plastic mold as the carrier, in the factory trained in bryophytes mat modules, greening construction directly fixed on the roof or the module. Small amount of medium in the module on metope, can satisfy the growth of the bryophytes, also making construction replacement maintenance process simple, basicly need watering after completion, depending on natural precipitation can survive sand bryophytes. Bryophytes is a commonly used bryophytes plant in vertical greening.

2) Miniascape: Miniascape is known as a silent poetry, the three-dimensional paintings (WeiJinSheng, 1998). Bryophytes to miniascape of decoration and local ornament effect for the entire bonsai often plays the effect that make the finishing point in the landscape tree stumps bonsai plant proper bryophytes, make whole bonsai more elegant, miniascape of bryophytes on the rocks is the maintenance and improvement of any other plants can not replace the commonly used in tile bryophytes on the stump bonsai methods for cultivation, while in the landscape bonsai uses the following three ways: one is the bryophytes, grinding to be sprinkled in the wettability of rock, wet places of place, water spray from time to time, about half a month to grow new bryophytes. Second, the potato powder potato flour malt flour and flour are mixed into mucilaginous shape. After cooling, the soft brush is used to evenly apply on the exposed rocks after water spraying or soaking. The third is to put the completed mountain stone potted landscape in a corner of the courtyard to avoid the wind, and use other pots nearby to hold water to increase the humidity of the air. According to the climate, water will be sprayed every day or every other day, and bryophytes can be naturally produced after a few months (Lin yunjia,2005).

3) Aquarium: In the plant communities, bryophytes have always been regarded as a transitional plant group from aquatic life to terrestrial life. Some bryophytes, such as Riccia fluitans L., Vesicularia, Taxiphyllum, have submerged or adhered to sunk and stone growth, often used as vegetation materials in the bottom bed of the water and land cylinders. Taxiphyllum, which has the characteristics of submerged growth or adherence to submerged trees and stones, is often used as a substrate vegetation in land and water tanks. Plagiomnium and Hypnum are often planted in the "mountain stone", "plain", "waterfall" and so on as the main scenery or ornament, because of their strong moisture resistance.

4) Flower and wood transportation ginseng preservation and configuration conservation: The stems and leaves of bryophytes have a strong water absorption and water retention capacity. Bryophytes is often used for packaging and transportation of fresh seedlings, or with a bandage, or a sowing cover when the fruit is grafted. And can be used as a fertilizer to increase the sand suction force. In addition, ginseng in China a leading posts on this site from fresh ginseng save method mentioned in the way of the fresh ginseng, fresh ginseng harvested from the ginseng planting base must be placed in the unpolluted moss in the northern mountainous area, and placed in the fresh-keeping cabinet at the temperature of $-5 \sim 5{ }^{\circ} \mathrm{C}$. At the same time, we must insist on spraying water regularly to bryophytes to keep the humidity of bryophytes. Fresh ginseng preserved with moss can be stored for 3-6 months at $0-4{ }^{\circ} \mathrm{C}$ in the refrigerator, while fresh ginseng preserved without moss can quickly perish. In the world of configuration conservation, the existence of bryophytes is also of great significance. Now, many cities, especially Shanghai in China, have realized that the use of bryophytes as the configuration conservation of flower cultivation can usually achieve good results.

\section{THE COMBINATION OF BRYOPHYTES PLANTS AND GARDEN ELEMENTS}

\section{A. The Combination of Bryophytes and Other Plants}

Many bryophytes belong to the epiphytes of trees, such as Bryum capillare Hedw., Haplohymenium triste (Ces.) Kindb. Many of these bryophytes are ornamental, highly drought resistant and highly resistant to human disturbance.

Some bryophytes tend to choose specific epiphytic tree species. In recent years, some scholars have found that host specificity of epiphytic bryophytes can be changed by the changes of site conditions such as latitude, altitude and bark humidity. Bryophytes do not show absolute host specificity to epiphytic tree species, but there is a dynamic rather than static relationship between them.

It is found that Salix babylonica, Pterocarya stenoptera C. DC, Ginkgo biloba L. and Cinnamomum camphora all have epiphytic phenomena. J. sinensis Fleisch. ox Broth. Often is often attached on Cinnamomum camphora. While Entodon compressus (Hedw.) C. Muell. tend to pick on Pterocarya stenoptera C. DC. Leskeella are closely related to Ginkgo biloba L.. No species of tree epiphytic bryophytes which has a tendancy to Salix babylonica were found. Therefore, if we choose J. sinensis Fleisch. or Broth. and Entodon compressus (Hedw.) C. Muell or other bryophytes, we should choose their preferred tree species. And Salix babylonica are suitable for the vast majority of trees, so we can consider the 
selection of Salix babylonica which has a wide range of applicability in the design of bryophytes landscape.

In the creation of the epiphytic bryophyte landscape of large trees, the following points should be paid to the attention of most people in order to make bryophytes rather than the trunk itself. At first, the height of the bryophytes is best controlled at $1.4 \sim 1.6 \mathrm{~m}$, the horizontal line of human sight, so that the architect's carefully configured moss landscape can be seen when people look forward to the front. Besides in order to guarantee the growth condition of bryophytes good, try to choose in the backlight side of the trunk cultivated. At last, try to choose the brightly colored tree epiphytic species to create a green effect.

The above methods of collocation of epiphytic mosses are introduced. Here are some models of bryophytes planting on land. The first mode is bryophytes with Zoysia japonica and tall trees to create the effect of sparse forest lawn. The combination of bryophytes and Zoysia not only allows bryophytes to grow vigorously, but also can completely cover the land, forming a more compact carpet effect. The second models are bryophytes with tall trees and more compact shrubs. Tall trees can choose Jue, camphor, and osmanthus trees. The shrubs can choose Rhododendron and Ligustrum lucidum.

\section{B. The Combination of Bryophytes Plants and Themselves}

In the survey, a variety of bryophytes in clustered together have high ornamental value. First in terms of color, bryophytes are mostly green, but the green degree of every species of bryophytes is not same. There are green, dark green, olive green, light green, sage green, yellow-green, etc.. So the collocation between bryophytes becomes easier to coordinate. For the first, bryophytes plants of the habitat must be the same or similar. In addition, it is necessary to set aside some development space for bryophyte when planting. Thirdly, we must consider the collocation of ornamental bryophytes.

Second bryophytes of ornamental collocation, mainly lies in the change of the terrain and bryophytes form, texture and color contrast. Most bryophytes are not very different in height, and it is easy to make the design monotonous without taking advantage of terrain fluctuations. Thus, the terrain is very important to shape. The overall shape and texture of bryophytes and the color difference also require careful consideration by the architect. The better way is to choose a kind of ornamental bryophyte as the main body bryophytes, combined with texture, color and form have certain differences in other varieties.

\section{The Combination of Bryophytes Plants and Garden Vignettes}

There are several bryophytes which can grow on rocks, such as Aerobryum speciosum Dozy \& Molk., Wijkia hornschuchii (Doz. Et Molk.) Crum, Anomobryum auratum (Mitt) Jaeg Hedw.) etc.. Therefore, if we hope that bryophytes can have a certain relationship with small garden ornaments, we should try to consider the materials of small garden ornaments. In the process of investigation, it is found that rocks with relatively easy weathering and relatively high organic matter are more suitable for bryophytes growth. So if you want to express as a Japanese garden, bryophytes covered with stone lantern of the lonely feeling, be sure to use a softer and more easily weathered stone material.

In addition, some bryophytes prefer decaying wood materials. These bryophytes include Pseudobarbella levieri (ren. et Card.) Nog., Oncophorus crispifolius (Mitt) Lindb., Leucobryum bowringii Mitt., and pseudor-triste. Broth.), Gymnostomum recurvirostre Hedw., et al.. Therefore, to convey a sense of historical antiquity, a moderate amount of sapropel wood combined with bryophytes can be used to create a special bryophytes landscape.

\section{CONCLUSION}

This paper has introduced the application of the bryophytes in the landscape for the future, providing certain theoretical basis and design suggestions, and giving the landscape architects ideas and part of the bryophytes configuration mode. In the next step, bryophytes will be screened and the adaptability of different bryophytes can be obtained by observing and experimentation. The bryophytes will be cultivated rationally according to their ecological habits. And the bryophytes with higher ornamental value will be widely applied and popularized.

\section{REFERENCES}

[1] An Li, Cao Tong, Yu Ying-hao. 2006. Bryophytes and environmental heavy metal pollution monitoring. Chinese Journal of Ecology, 25(2):201-206.

[2] Breil D A, Moyle S M. 1976. Bryophytes used in construction of bird nests. Bryologist, 79(1):95-98.

[3] Cameron A J, Nickless G. 1977. Use of mess as collectors of airborne heavy metals near a smelting complex. Water, Air, \& Soil

[4] OPollution, 7(1):117-125

[5] Chen Bang-jie, Wu Peng-cheng, Pan Chieh C, Pan Cheng W. 1964. The Chinese epiphytic bryophytesresearch(one). Journal of University of Chinese Academy of Sciences, 9(3):213-276.

[6] Chen Jun-he, Jiang Ming, Zhang Li. 2010. Application of Bryophytes in Landscaping. Guangdong Landscape Architecture, 32 (1):31-34.

[7] Chen Li-hua, Yu Xin-xiao, Zhang Dong-sheng, Gao Jia-rong. 2002. Hydrological process of bryophyte of Abies fabris

[8] forest in Gongga Mountain, 24(4)60- 63.

[9] Dwh, W. 1993. The effects of cryptogams on mineral substrates. Special Publications.

[10] Herben, T. 1984. A. J. E. Smith (ed.) Bryophte Ecology. Folia Geobotanica, 19(1): 100-100.

[11] Hao Zhan-qin. 2000. The north slope of plant community diversity and its gradient structure analysis. The Shenyang Institute of Applied Ecology in Chinese Academy of Sciences.

[12] Jiao Yun-hong, Ye Jia. 2006. Utilization status of bryophyta in the gardern city. Journal of biology, 23 (2):48-49.

[13] Li Xue-ye. 2008. The application of bryophytes in the landscape and artificial breeding technology. The Modern Agricultural Science and Technology, (23):81-81.

[14] Lin Yun-jia. 2005. The cultivating method of bonsai bryophytes Flowers, (8):14-14.

[15] Reimers E. 1977. Population dynamics in two subpopulations of reindeer in svalbard. Arctic \& Alpine Research, 9(4): 369-381.

[16] Sun Jun-feng. 2013. The Cultivating Methods and Building bryophyteses Garden. Agricultural Science and Technology and Information Technology: modern landscape architecture, (11): 63-68. 
[17] Wei Hai-ying, Fang Yan-ming. 2004. Review on Bryophyte and Airborne Heavy Metal Pollution Biomonitoring, Journal of Nanjing Forestry University (Natural Science Edition), (5): 77-81.

[18] Wang Jian, Cao Tong, Wang Min, Chen Hui. 2007. Biodiversity and It's Characteristics of Bryophytes in the Suzhou Gardens. Acta Botanica Boreali-Occidentalia Sinica, 27(6):1239-1246.

[19] Wei Jin-sheng. 1998. The Chinese bonsai art. Shanghai Science and Technology Publishing House.

[20] Wu Peng-cheng. 1998. The bryophytes plant biology. Science Press.

[21] Xu Jie, Bai Xue-liang, Yang Chi, Zhang Ping. 2003. Study on diversity and binding-sand effect of bryophytes on biotic crusts of fixed dunes. Acta Phytoecologica Sinica, 27 (4): 545-551.

[22] Zhou Zhi-jing, Zhu Ya-lan, Ding Shao-gang. 2009. bryophytes plants and their application in landscape architecture. China's Urban Forestry, 7(1):21-23. 